\title{
Uusioersily
}

\section{Experimental study and analysis on flame lengths induced by wall-attached fire impinging upon an inclined ceiling}

Zhang, X., Hu, L., Delichatsios, M., \& Zhang, J. (2018). Experimental study and analysis on flame lengths induced by wall-attached fire impinging upon an inclined ceiling. Proceedings of Combustion Institute, 37(3), 3879-3887. https://doi.org/10.1016/j.proci.2018.06.203

Link to publication record in Ulster University Research Portal

\section{Published in:}

Proceedings of Combustion Institute

Publication Status:

Published online: 20/07/2018

DOI:

10.1016/j.proci.2018.06.203

\section{Document Version}

Author Accepted version

\section{General rights}

Copyright for the publications made accessible via Ulster University's Research Portal is retained by the author(s) and / or other copyright owners and it is a condition of accessing these publications that users recognise and abide by the legal requirements associated with these rights.

\section{Take down policy}

The Research Portal is Ulster University's institutional repository that provides access to Ulster's research outputs. Every effort has been made to ensure that content in the Research Portal does not infringe any person's rights, or applicable UK laws. If you discover content in the Research Portal that you believe breaches copyright or violates any law, please contact pure-support@ulster.ac.uk. 


\title{
Experimental study and analysis on flame lengths induced by wall-attached fire impinging upon an inclined ceiling
}

\section{Xiaolei Zhang ${ }^{\mathrm{a}}$, Longhua $\mathrm{Hu}^{\mathrm{a} *}$, Michael A. Delichatsios ${ }^{\mathrm{a}, \mathrm{b}}$,}

Jianping Zhang ${ }^{\mathrm{c}}$

\author{
${ }^{a}$ State Key Laboratory of Fire Science, \\ University of Science and Technology of China, \\ Hefei, Anhui, 230026, China \\ ${ }^{\mathrm{b}}$ Department of Mechanical and Industrial Engineering, \\ Northeastern University, Boston, USA \\ ${ }^{\mathrm{c}}$ FireSERT, School of Built Environment,
} Ulster University, Newtownabbey, BT37 0QB, Northern Ireland, UK

*Corresponding author: Tel: (86) 551 63606446; Fax: (86) 551 63601669; Email address: hlh@ustc.edu.cn; Postal address: State Key Laboratory of Fire Science, University of Science and Technology of China, Hefei, Anhui, 230026, China.

\section{Colloquium: Fire research}

Total length of the paper:6196 (method 1)

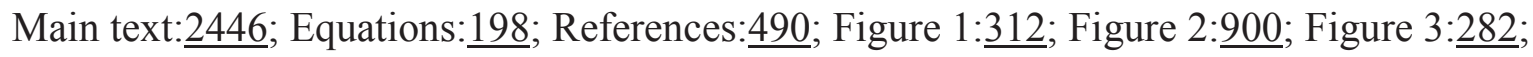

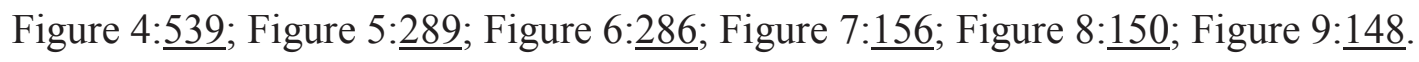




\section{Abstract}

Experiments were conducted to investigate the flame lengths induced by a wall-attached fire impinging upon an inclined ceiling, which has not been quantified previously. The flame lengths beneath the ceiling were measured in the directions both normal- $(x$ direction) and parallel $(y$ direction) to the intersection line of the wall and ceiling for 576 experimental conditions, involving various heat release rates, source-ceiling heights and ceiling inclination angles (from $-20^{\circ}$ to $20^{\circ}$ ). The measured values were found to be essentially different from previous data and correlations for fire impingement without wall, and at the same time, have a complex variation nature with inclination angle. The flame lengths in the $x$ direction increased, whereas that in the $y$ direction decreased with increasing of the ceiling inclination angle. The measured flame lengths were then analyzed regarding the buoyancy effect (gravitational component along the ceiling) in two aspects: one is due to the change of the impinged flow velocity field distribution over the ceiling and the other is due to the formation of corner vortex rotating flow. The flame lengths in either direction normalized by the ceiling height $(H)$ was found to be proportional to $\left(H_{\text {wall }, 5} H\right) / H$ (reflects the fraction of the unburned fuel after impingement) where $H_{\text {wall } f}$ is the free flame height for the wall-attached fire. The effect of the angle was then further accounted for by multiplying $\left(H_{\text {wall }, 5}-H\right) / H$ with $(1+\sin \theta) / 2$ for the flame lengths in the $x$-direction, and dividing $\left(H_{\text {wall }, 5}-H\right) / H$ by $(1+\sin \theta) / 2$ for the flame lengths in the $y$-direction. New models were finally obtained to correlate the impinging flame lengths in the two directions. This study provides quantitative data and basic understanding of the flame length beneath an inclined ceiling induced by wall-attached fire impingement, which has a ceiling flow structure essentially different from other impinging configurations reported previously.

Key words: Impinging flame length; inclined ceiling; wall-attached fire; buoyancy (gravitational) component along ceiling; rectangular source. 


\section{Introduction}

The impinging flame length in ceiling jet is an important parameter [1-13] to estimate the direct heat flux upon the ceiling and the radiation to flammable objects below the ceiling. The earliest experiments to measure the impinging flame lengths was done by You and Faeth [3] for unconfined horizontal ceiling using axi-symmetric sources (0.36-7.89 kW). Later, Heskestad and Hamada [4] performed experiments for larger heat release rates $(92.6-764 \mathrm{~kW})$. They showed that the radial flame length was nearly a linear function of the cut-off flame height, $H_{\text {free }} f^{-H}$, where $H_{\text {free } f}$ is free flame height and $H$ is ceiling height. Recently, the flame length beneath an unconfined ceiling was analyzed and correlated by Ding et al. [5]. Wang et al. [6], through numerical simulations, found that the flame length normalized by the ceiling height $H_{e, f} / H$ was a function of $\left(H_{\text {free,f }}-H\right) / H$. Some experiments were also reported on flame lengths for confined ceiling with fire at the corner [7-9] or in a long-narrow (corridor) structure [13].

The above studies focused on the impinging flame length beneath a horizontal ceiling. However, in practice, there are also commonly buildings having inclined roofs $[11,14,15]$ for which the correlations for horizontal ceiling are not applicable. The only report on impinging flame length beneath an inclined ceiling is the recent one by Zhang et al. [11], in which the impinging flame lengths for different ceiling inclination angles $\left(0-20^{\circ}\right)$ were measured and correlated for a free fire impingement (without wall). We note that there is still no report on the impinging flame length induced by wall-attached fires beneath an inclined ceiling, where the inclination angle can be either negative or positive (or the ceiling-wall angle can be less than $90^{\circ}$ or larger than $90^{\circ}$ ). The flow structure and impinging flame length in this case should be essentially different from that produced 
by a free fire (without wall), as a result of complex coupling effects of wall-constraint air entrainment, corner impinging flow and buoyancy component along the ceiling.

Therefore, experiments were conducted to investigate the flame lengths induced by wall-attached fire impingement upon an inclined ceiling. The impinging flame lengths were measured in the directions both normal- ( $x$ direction) and parallel ( $y$ direction) to the wall-ceiling intersection for various heat release rates (HRR), source-ceiling heights and ceiling inclination angles. Non-dimensional correlations were proposed to describe these two quantities.

\section{Experiments}

Figure 1 shows the experimental setup. A rectangular mica smooth plate $(2 \mathrm{~m} \times 1.25 \mathrm{~m})$ with low thermal conductivity of $0.035 \mathrm{~W} /(\mathrm{m} \cdot \mathrm{K})$ having good heat resistance performance was used to simulate the wall, and another one (with the same properties, $2 \mathrm{~m} \times 1 \mathrm{~m}$ ) simulating the ceiling. Five ceiling inclination angles $(\theta),-20^{\circ},-10^{\circ}, 0^{\circ}, 10^{\circ}$ and $20^{\circ}$ were considered. Such ceiling inclination angles cover most of the building roof conditions [16].

For negative ceiling inclination angles $\left(-20^{\circ}\right.$ and $\left.-10^{\circ}\right)$, three rectangular gaseous fire sources with the dimensions $L$ (length) $\times W$ (width) $16.88 \mathrm{~mm} \times 16.88 \mathrm{~mm}, 47.75 \mathrm{~mm} \times 5.97 \mathrm{~mm}$ and 142.5 $\mathrm{mm} \times 2 \mathrm{~mm}$ were used, and three source-ceiling heights $0.38 \mathrm{~m}, 0.475 \mathrm{~m}$ and $0.57 \mathrm{~m}$ were considered. For horizontal $\left(0^{\circ}\right)$ and positive ceiling inclination angles $\left(10^{\circ}\right.$ and $\left.20^{\circ}\right)$, four rectangular gaseous fire sources with the dimensions $L$ (length) $\times W$ (width) $16.88 \mathrm{~mm} \times 16.88 \mathrm{~mm}, 47.75 \mathrm{~mm} \times$ $5.97 \mathrm{~mm}, 71.25 \times 4 \mathrm{~mm}$ and $142.5 \mathrm{~mm} \times 2 \mathrm{~mm}$ were used, and five source-ceiling heights $0.38 \mathrm{~m}$, $0.475 \mathrm{~m}, 0.57 \mathrm{~m}, 0.665 \mathrm{~m}$ and $0.72 \mathrm{~m}$ were considered. The fire sources were arranged with longer side attached the wall. Propane was used as fuel with supply rate controlled by a flow rate meter $\left(0.01 \mathrm{dm}^{3} / \mathrm{min}\right)$. The HRRs ranged from 2.23 to $19.64 \mathrm{~kW}$. The flame Froude number $F r_{f}<5$ 
$\left(F r_{f}=\frac{u_{0}}{(g d)^{1 / 2}(S+1)^{3 / 2}\left(\rho_{0} / \rho_{\infty}\right)^{1 / 4}\left(\overline{\Delta T_{f}} / T_{\infty}\right)^{1 / 2}}\right.$ [17], with $d$ replaced by fire source perimeter $(2 L+2 W))$ and flame Grashof number $G r \geq G r_{\text {crit }} \approx 10^{9} \quad\left(G r=\frac{\overline{\Delta T_{f}} / T_{\infty} g H_{\text {wall }, f}^{3}}{v_{\infty}^{2}}\right)[18,19]$, to assure that flames were buoyancy-controlled and fully turbulent. $u_{0}$ is fuel flow velocity at nozzle exit, $g$ gravitational acceleration, $S$ air to fuel mass stoichiometric ratio, $\rho_{0}$ fuel density, $\rho_{\infty}$ ambient air density, $\overline{\Delta T_{f}}$ mean flame temperature rise, $T_{\infty}$ ambient temperature, $G r_{\text {crit }}$ critical flame Grashof number, $H_{\text {wall }, f}$ wall-attached flame height, $v_{\infty}$ kinematic viscosity. 576 experimental conditions, involving various HRRs, source-ceiling heights and ceiling inclination angles, were considered. Each case was repeated three times.

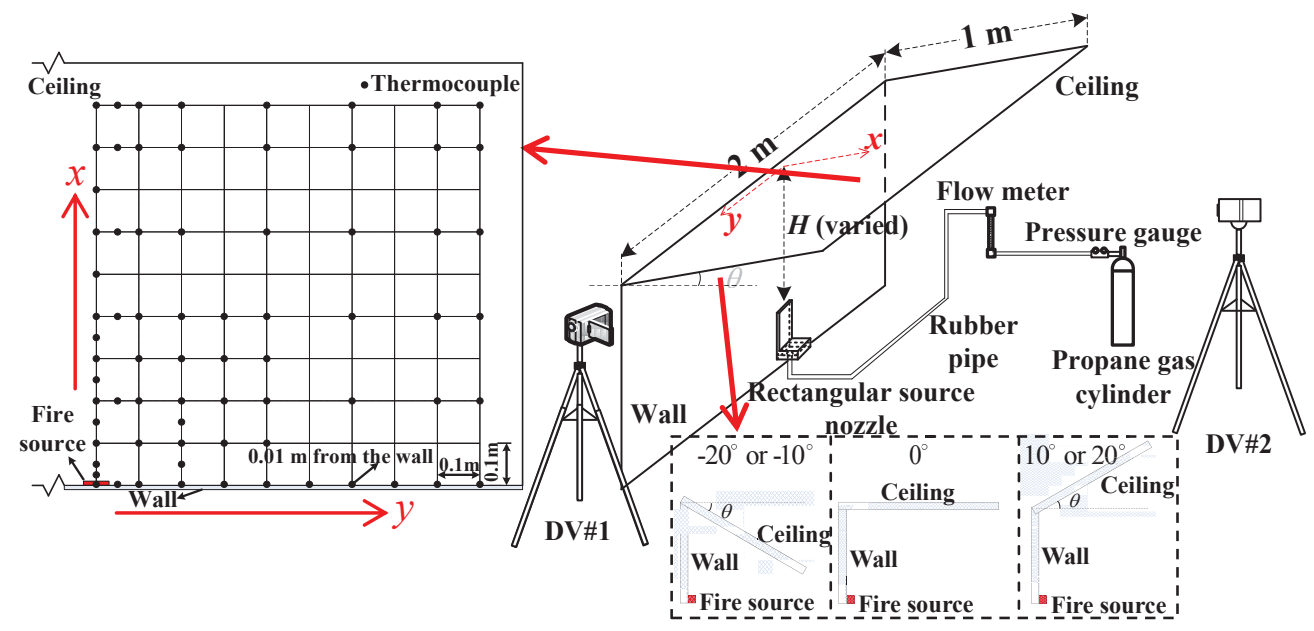

Figure 1: Experimental setup.

Two digital cameras (DV) with $1920 \times 1280$ pixels $(25 \mathrm{fps})$ were employed to record the impinging flame lengths beneath ceiling. One was parallel to wall (DV\#1) to record the flame lengths in $x$ direction (normal to wall-ceiling intersection), whereas the other perpendicular to wall (DV\#2) to record the impinging flame lengths in $y$ direction (parallel to wall-ceiling intersection). The impinging flame length was obtained based on the $50 \%$ flame appearance probability [11, 20, 21], from time series flame images recorded by the camera (60 s, 1500 frames) as did in $[11,20,22]$. 
The corresponding flame height $H_{\text {wall,f }}$ without ceiling for such wall-attached fire was also measured. The temperature profile in the impinged ceiling flow was measured by K-type thermocouples (bead diameter: $0.5 \mathrm{~mm}$ ) with radiation error corrected [23]. 72 thermocouples were installed at $0.015 \mathrm{~m}$ beneath the ceiling. The locations of $50 \%$ of the flame appearance probability were found to be consistent with the temperature of about $780-880 \mathrm{~K}$.

\section{Results and Discussion}

\subsection{Impinging flame lengths in the two directions}

Figures 2(a) and (b) show the instantaneous photos and the corresponding flame appearance probability of flame along the ceiling in the $x$ direction (normal to intersection, $H_{n, f}$ ) for the five angles; and Figures 2(c) and (d) show those in the $y$ direction (parallel to intersection, $H_{p, f}$ ). The flame length in the $x$ direction increases, whereas that in the $y$ direction decreases, with increasing of ceiling inclination angle. This is also well indicated by the quantitative data in Fig. 3.

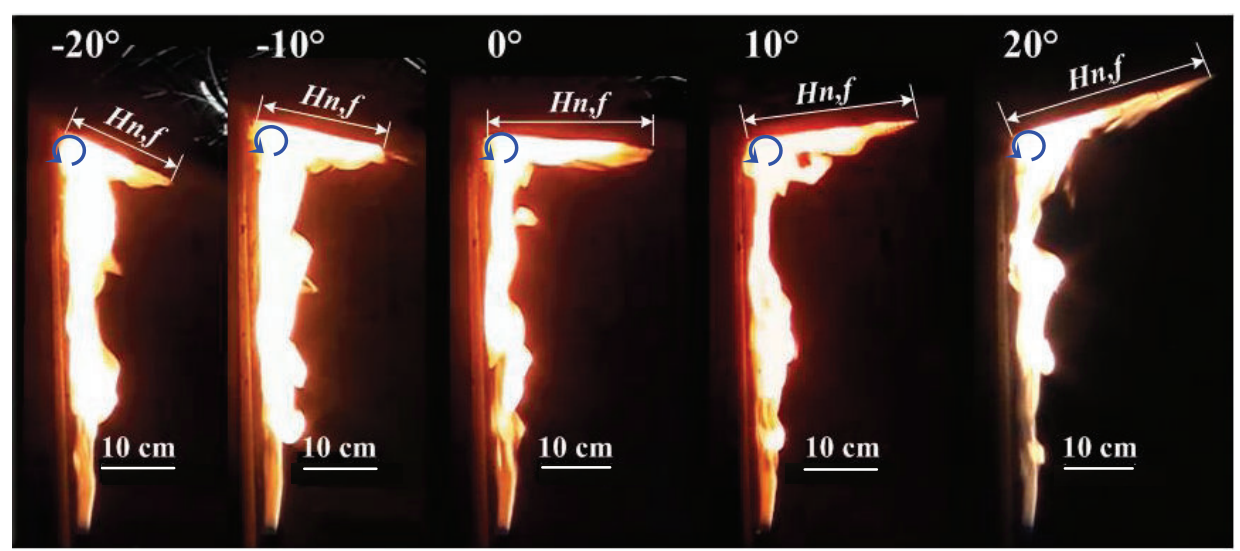

(a) Typical instantaneous photos of flame along the ceiling in the $x$ direction. 


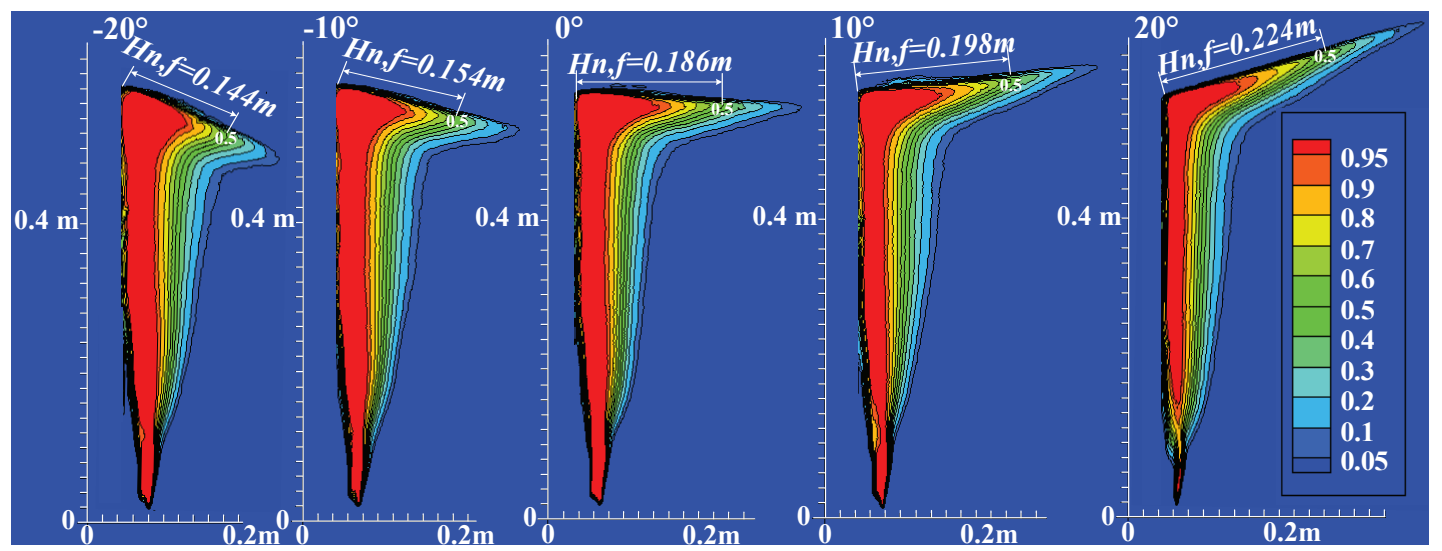

(b) Flame length quantification of $H_{n, f}$ ( $x$ direction) based on flame appearance probability contour.

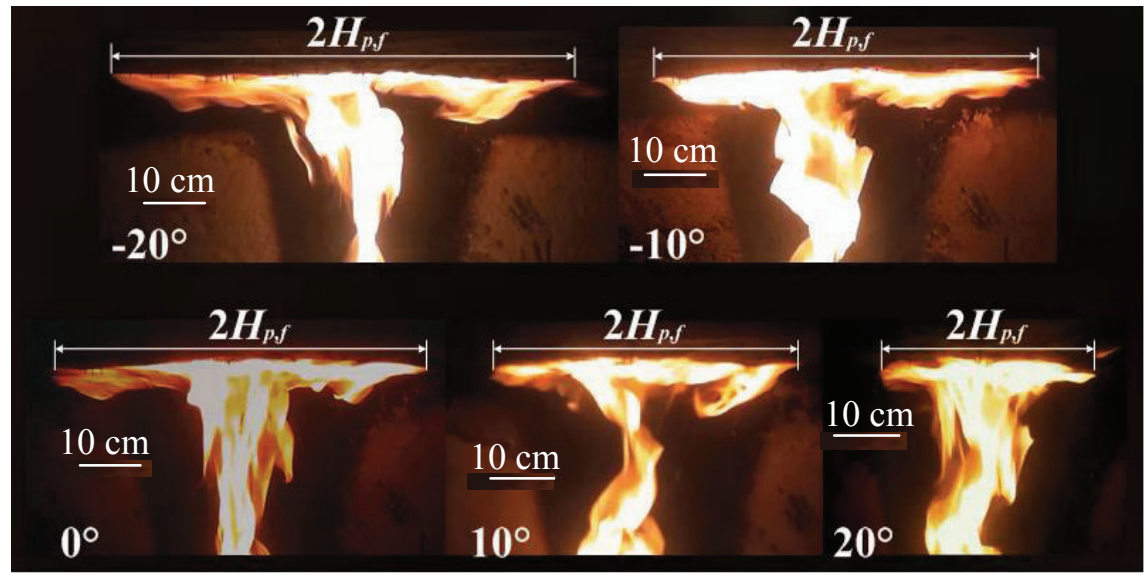

(c) Typical instantaneous photos of flame along the ceiling in the $y$ direction.

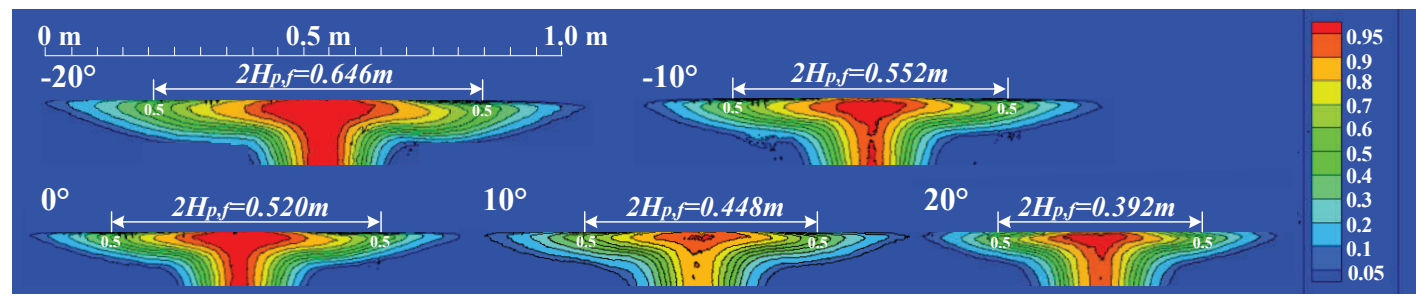

(d) Flame length quantification of $H_{p, f}(y$ direction) based on flame appearance probability contour.

Figure 2: Impinging flame length quantification in the two directions (burner: $16.88 \mathrm{~mm}(L) \times$ $16.88 \mathrm{~mm}(W) ; H=0.57 \mathrm{~m} ; \dot{Q}=13.39 \mathrm{~kW})$.

Figure 3 also shows that, for the angle of $0^{\circ}$, the flame length in the $y$ direction is remarkably larger than that in the $x$ direction. This could be attributed to that in the $y$ direction the flame extends with rotating vortices (marked by blue circle in Fig. 2(a), the flow rotates downward near the wall surface) generated in the corner along the intersection (these vortices were also observed in corridor fire ceiling corner flows [13]). Due to these vortices, more un-burnt fuel is driven to flow along the 
intersection in the $y$ direction, resulting in relative longer flame length. The evolution of flame lengths with inclination angle described above can be explained by the effect of the inclination angle on the un-burnt fuel movement and flow distribution as shown in Figs. 4 and 5.

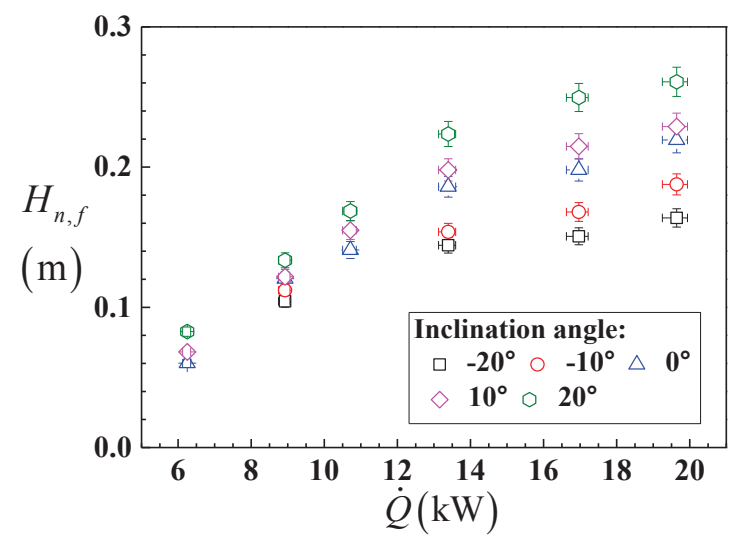

(a) $x$ direction

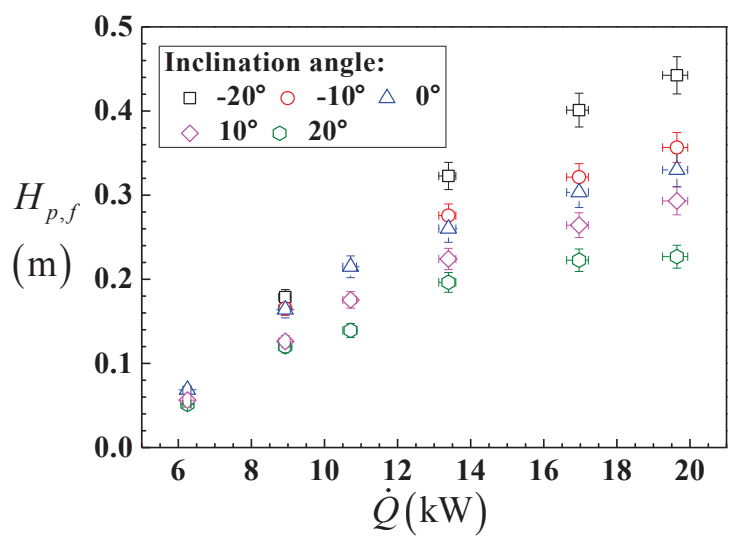

(b) $y$ direction

Figure 3: Measured impinging flame lengths in the two directions versus heat release rates

(burner: $16.88 \mathrm{~mm} \times \mathbf{1 6 . 8 8} \mathrm{mm} ; \boldsymbol{H}=\mathbf{0 . 5 7} \mathrm{m}$ ) for various ceiling inclination angles.

For negative ceiling inclinations (Fig. 4(a) $\left(-20^{\circ}\right.$ or $\left.-10^{\circ}\right)$ ), the gravitational (buoyancy) component along ceiling $B_{1}$ is against the un-burnt fuel velocity $u_{f u e l}$ in the $x$ direction, which decelerates and stagnates the un-burnt fuel resulting in a shorter flame length in this direction than that for a horizontal ceiling (i.e., $\theta=0^{\circ}$ ). The buoyancy potential driven by gravitational component $B_{1}$ (towards the corner) will lead more un-burnt fuel flow bending back to the corner ( $y$ direction) and enhance the rotating vortices that drive more un-burnt fuel flowing along the intersection in the $y$ direction. $B_{1}$ decreases with the increasing of ceiling inclination angle $\theta$ (from $-20^{\circ}$ to $0^{\circ}$ ) since $B_{1}=|B \sin \theta|$. So, the impinging flame length in the $x$ direction increases, while that in the $y$ direction decreases, with increasing of ceiling inclination angles (from $-20^{\circ}$ to $0^{\circ}$ ).

For positive ceiling inclinations (Fig. $4(\mathrm{~b})\left(10^{\circ}\right.$ or $\left.\left.20^{\circ}\right)\right), B_{1}$ is in the same direction as $u_{f u e l}$ in the $x$ direction parallel to ceiling, which accelerates the un-burnt fuel and hence resulting in larger impinging flame length in this direction than a horizontal ceiling (i.e., $\theta=0^{\circ}$ ). Meanwhile, the 
buoyancy potential driven by gravitational component $B_{l}$ drives the impinged flow leaving the corner. And it also suppresses the rotating vortices at the corner. One can imagine that when ceiling inclination angle becomes very large (i.e., $\theta \rightarrow 90^{\circ}$ ), such rotating vortices will be completely suppressed. All these result in less un-burnt fuel flowing along the intersection in the $y$ direction. For this condition, $B_{1}$ increases with increasing of ceiling inclination angle $\theta$ (from $0^{\circ}$ to $20^{\circ}$ ) since $B_{1}=B \sin \theta$. So, the impinging flame length in the $x$ direction increases, meanwhile that in the $y$ direction decreases, with increase of ceiling inclination angles (from $0^{\circ}$ to $20^{\circ}$ ).
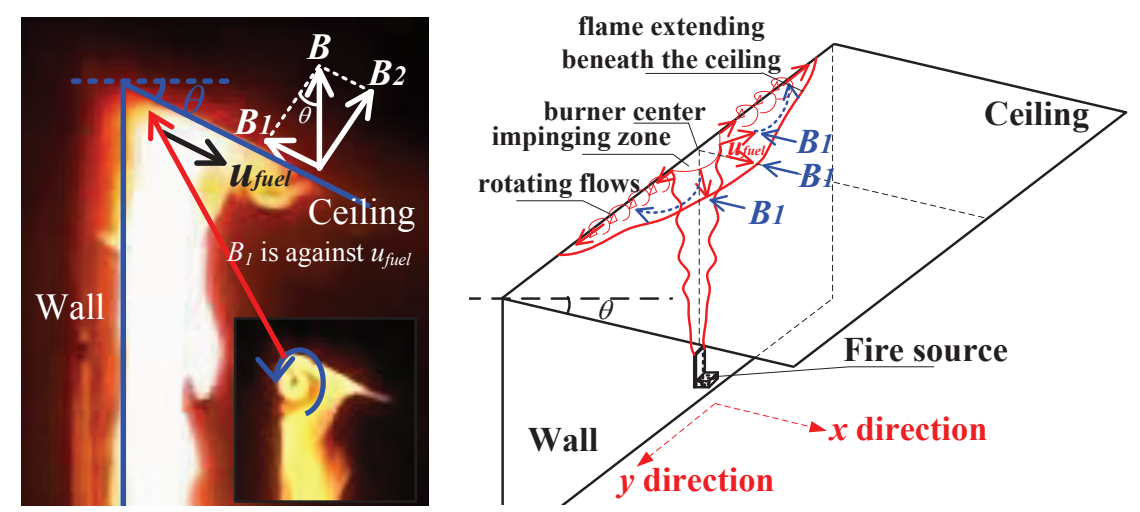

(a) $-20^{\circ}$ or $-10^{\circ}$
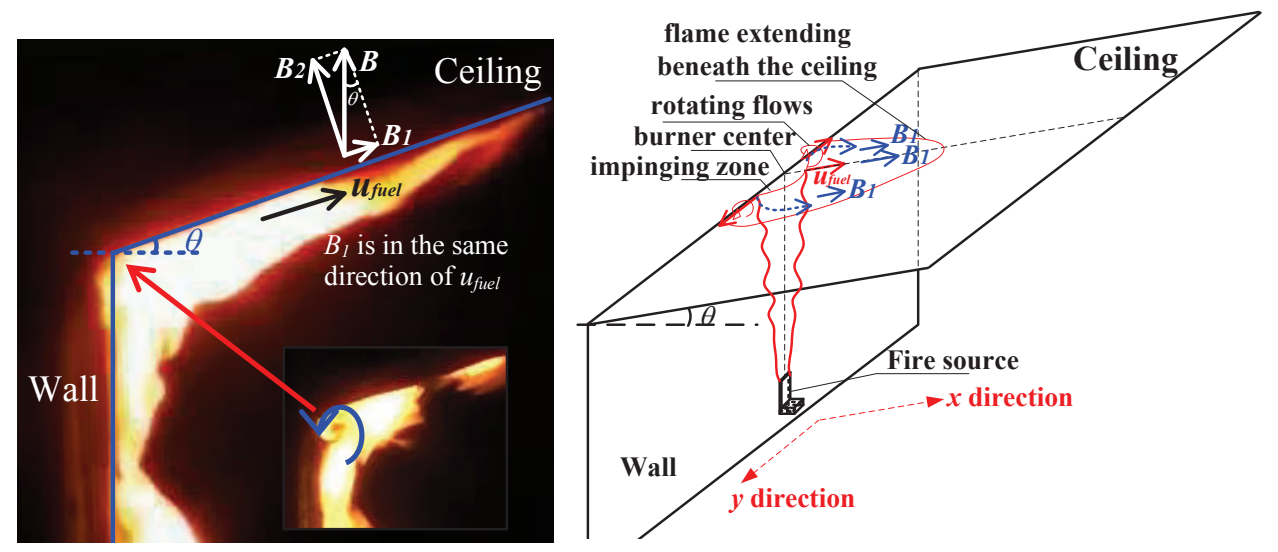

(b) $10^{\circ}$ or $20^{\circ}$

Figure 4: Physics of buoyancy effect (gravitational component along ceiling) on the impinging

\section{flame lengths at negative (a) and positive (b) ceiling inclination angles.}

The effect of $B_{l}$ on the impinged flow structure hence the un-burnt fuel distribution can be more clearly substantiated by the measured temperature isotherms in Fig. 5. Figure 5 shows that the 
isotherm gradient in the $x$ direction increases with the decreasing of the inclination angle $\left(0^{\circ}\right.$ to $\left.-20^{\circ}\right)$ which is due to that $B_{1}$ is against the un-burnt fuel velocity in the $x$ direction. The isotherm gradient in $y$ direction increases with the increasing of the inclined angle $\left(0^{\circ}\right.$ to $20^{\circ}$, consisted with the temperature profiles in Fig. 8 in [24] and Fig. 6 in [25] for unconfined inclined ceilings) as the heat flow will be driven to leave the corner by $B_{1}$ which was also proved by the velocity profile reported in Fig. 6 in [25]. This is a new finding which shows that the buoyancy (gravitational) component along the ceiling has opposite effect on impinging flame lengths in the two directions.

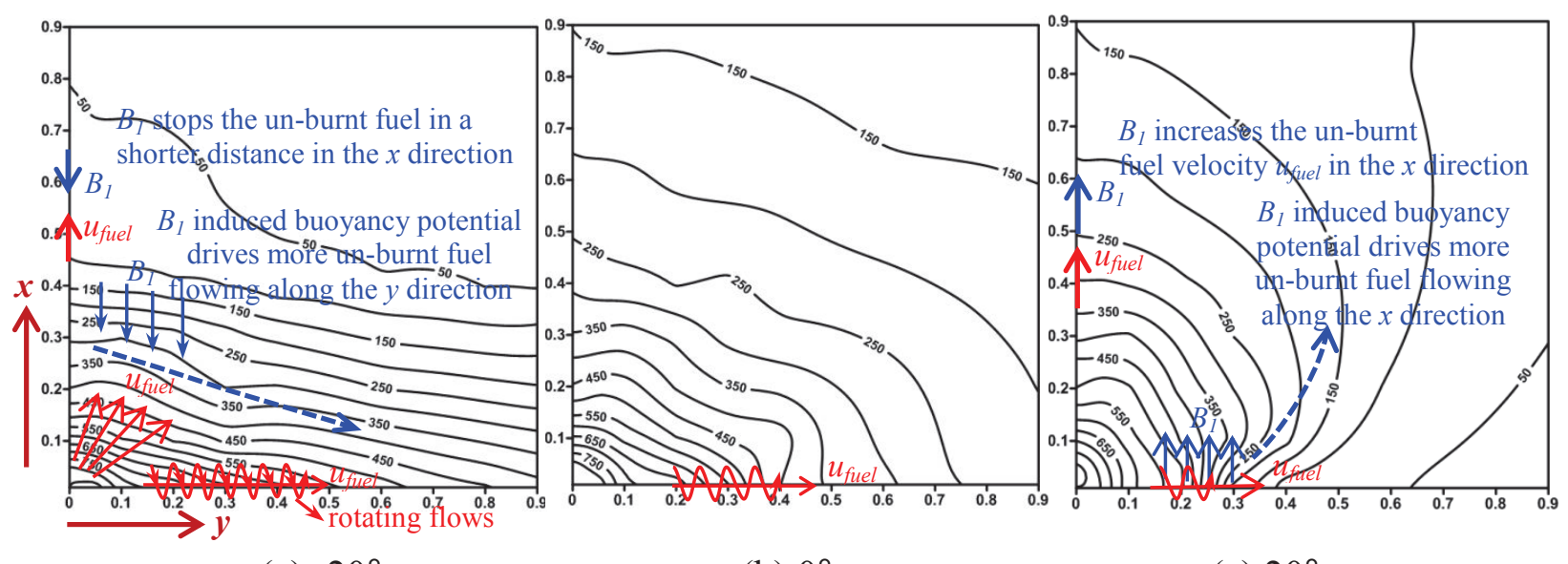
(a) $-20^{\circ}$
(b) $0^{\circ}$
(c) $20^{\circ}$

Figure 5: The isotherms (Unit: ${ }^{\circ} \mathrm{C}$ ) of ceiling inclination angles $-20^{\circ}, 0^{\circ}$ and $20^{\circ}$ (burner: 16.88

$$
\mathrm{mm} \times 16.88 \mathrm{~mm} ; H=0.57 \mathrm{~m} ; \dot{Q}=13.39 \mathrm{~kW}) \text {. }
$$

\subsection{Analysis and correlations}

In the previous studies [3-12], there were several correlations proposed for the flame lengths beneath an un-confined horizontal ceiling induced by free fire impingement, which were either expressed as $\frac{H_{e, f}}{H}=\operatorname{func}\left(\frac{\dot{Q}}{\rho_{\infty} c_{p} T_{\infty} \sqrt{g} H^{5 / 2}}\right)[9,11]$, or as $H_{e, f}=f u n c\left(H_{f r e e, f}-H\right)[6,12]$. In [9], a correlation for the impinging flame lengths $H_{e, f}$ beneath an unconfined horizontal ceiling is proposed as following 


$$
\frac{H_{e, f}+H}{H}=3.1\left(\frac{\dot{Q}}{\rho_{\infty} c_{p} T_{\infty} \sqrt{g} H^{5 / 2}}\right)^{2 / 5}
$$

Based on the relation of free flame height with HRR as following [26]

$$
\frac{H_{\text {free }, f}}{d}=3.5\left(\frac{\dot{Q}}{\rho_{\infty} c_{p} T_{\infty} \sqrt{g} d^{5 / 2}}\right)^{2 / 5}
$$

Eq. (1) can be rearranged as

$$
H_{e, f} / H=0.89\left(H_{\text {free,f }}-H\right) / H
$$

In [6], the following correlation was proposed,

$$
H_{e, f} / H=1.13\left[\left(H_{\text {free }, f}-H\right) / H\right]^{0.78}
$$

Figure 6(a) presents $\frac{H_{e, f}}{H}$ against $\frac{H_{\text {wall }, f}-H}{H}\left(H_{\text {wall }, f}\right.$ is the wall flame height without the ceiling, $\left.\Pi=\frac{H_{\text {wall }, f}-H}{H}\right)$ for the data of this work in $x$ direction for inclination angle of $0^{\circ}$, and those measured by Zhang et al. [11] as well as the predictions by Eqs. (3) and (4) for free fire impingement without wall $\left(\Pi=\frac{H_{f r e e, f}-H}{H}\right)$. It shows the normalized impinging flame lengths in $x$ direction without wall (data in [11] and the predictions by Eqs. (3) and (4)) are significantly larger than the present work with wall, which is due to flow rotating vortices in the corner as discussed in section 3.1. It is found that $\frac{H_{n, f}}{H}$ is almost proportional to $\frac{H_{\text {wall }, f}-H}{H}$ for the present study, however, the proportional constant is larger as the inclination angle is larger (Fig. 6(b)). 

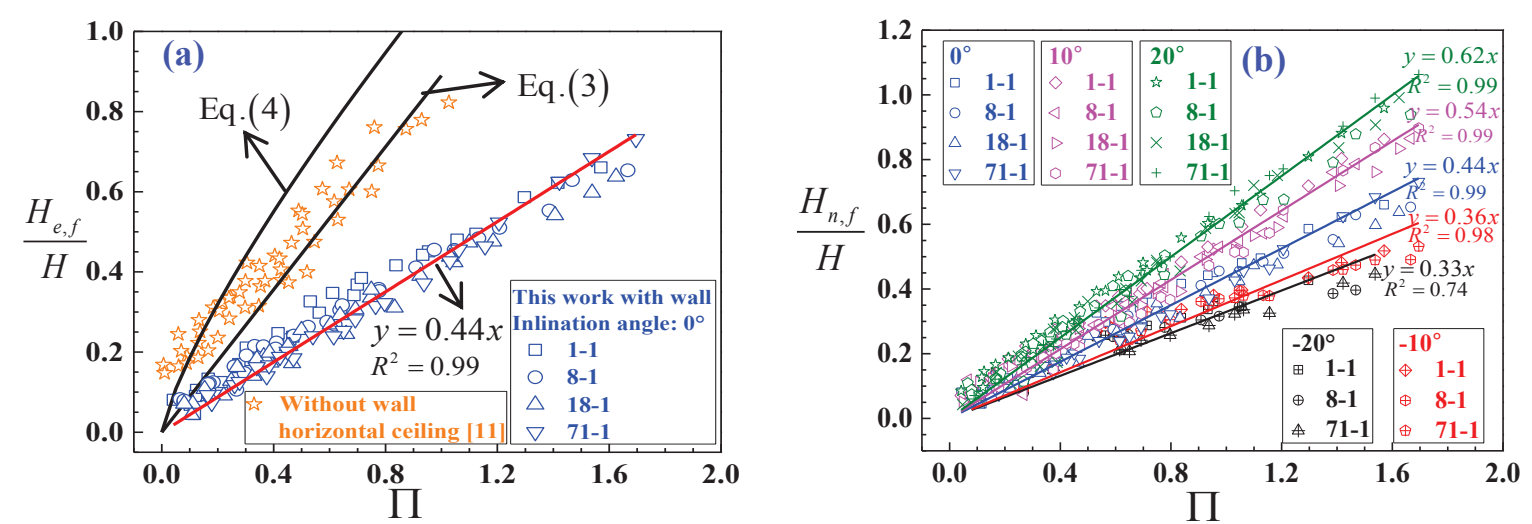

Figure 6: (a) Normalized impinging flame lengths in the $x$ direction versus the normalized

cut-off flame height and comparison with previous data [11] as well as the correlations

proposed in $[6,9]$ for free fire impingement without the effect of the wall for horizontal ceiling;

and (b) for all inclination angles.

In the impingement region, continuity gives $\dot{m}_{x}+\dot{m}_{\text {wall }}=\dot{m}$, where $\dot{m}_{x}$ and $\dot{m}_{\text {wall }}$ are the mass of unburned fuel flow in $x$ direction and opposite direction towards the wall just after impingements, $\dot{m}$ is the mass of unburned fuel flow just before impingement. Conservation of momentum in the direction along the ceiling gives $\dot{m}_{x} u_{\text {fuel }}-\dot{m}_{\text {wall }} u_{\text {fuel }}=\dot{m} u_{\text {fuel }} \sin \theta, u_{\text {fuel }}$ is velocity at the impingement point, and then we have $\dot{m}_{x}=\dot{m}(1+\sin \theta) / 2$. Then, we further plot the normalized impinging flame lengths in $x$ direction $\frac{H_{n, f}}{H}$ against a modified cut-off wall-attached flame height $\frac{1+\sin (\theta)}{2} \frac{H_{\text {wall, },}-H}{H}$ as shown in Fig. 7. The including of factor $\sin (\theta)$ is also to account for the buoyancy component along the ceiling (affecting the un-burnt fuel distribution after impingement) expressed as $B_{1}=|B \sin \theta|$ as discussed in section 3.1. It is also noted that when the ceiling inclination angle becomes very large (i.e., $\theta \rightarrow 90^{\circ}$ or $\sin (\theta) \rightarrow 1$ ), the impinging flame lengths $H_{n, f}$ in $x$ direction should be just approaching $H_{\text {wall }, f} H$ (as satisfied by $\frac{1+\sin (\theta)}{2}=1$ ). Figure 7 shows that the data for various inclination angles can be well correlated, 


$$
\frac{H_{n, f}}{H}=0.91\left(\frac{1+\sin (\theta)}{2} \frac{H_{w a l l, f}-H}{H}\right)
$$

It is noted that the rotating vortices in the corner drive more un-burnt fuel flowing along the intersection in the $y$ direction, in addition to the impinging and buoyancy effects accounted by above term $(1+\sin \theta) / 2$. So, the asymptotic value of $H_{n, f}$ in Eq. (5) at $\theta=90^{\circ}\left(0.91\left(H_{\text {wall }, f}-H\right)\right)$ is a bit smaller than the rationale value $\left(H_{\text {wall }, f}-H\right)$.

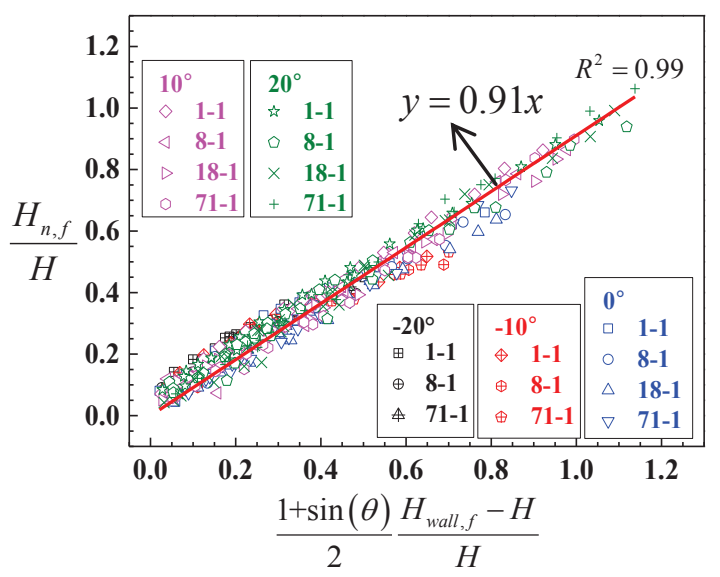

Figure 7: Normalized impinging flame lengths in $\boldsymbol{x}$ direction versus the modified normalized cut-off wall flame height $\left(H_{\text {wall, }}-H\right) / H$ including the effect of ceiling inclination angle.

Figure 8 presents $\frac{H_{n, f}}{H} \times \frac{H_{p, f}}{H}$ versus $\frac{H_{\text {wall }, f}-H}{H}$. This is based on physically that $\frac{H_{n, f}}{H} \times \frac{H_{p, f}}{H}$ reflects the ratio of the flame area for air entrainment beneath ceiling to the area for air entrainment during the flame rising up to ceiling height, which should be a function of the ratio of un-burned fuel after impingement to burned fuel before the impingement $\frac{H_{\text {wall, } f}-H}{H}$. The data for various inclination angles can be correlated well by (or namely, the combination in LHS of Eq. (6) represents the flame surface area for air mass entrainment, which is to be proportional to the amount of the un-burnt fuel (RHS of Eq. (6)) for mass/energy conservation)

$$
\frac{H_{n, f}}{H} \times \frac{H_{p, f}}{H}=0.33\left(\frac{H_{\text {wall }, f}-H}{H}\right)^{2}
$$




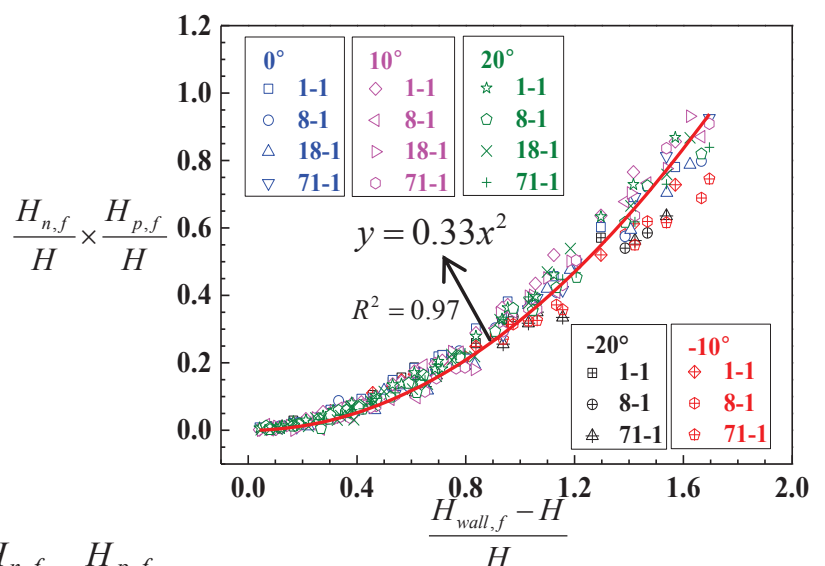

Figure 8: Plot of $\frac{H_{n, f}}{H} \times \frac{H_{p, f}}{H}$ against the normalized cut-off wall flame height $\left(\boldsymbol{H}_{\text {wall, }, \boldsymbol{H}} \boldsymbol{H}\right) / \boldsymbol{H}$ for various ceiling inclination angles.

Then, based on Eq. (5) and Eq. (6), the impinging flame length in $y$ direction $\left(H_{p, f}\right)$ can be solved as

$$
\frac{H_{p, f}}{H}=0.36 \frac{H_{\text {wall }, f}-H}{H} / \frac{1+\sin (\theta)}{2}
$$

Figure 9 shows that the values of $\frac{H_{p, f}}{H}$ in $y$ direction predicted by Eq. (7) agree well with the measured values for various experimental conditions. It is noted that the asymptote of Eq. (7) at $\theta=$ $90^{\circ}$ has no physical meaning as there is no flame impingement in this case, that it is non-applicable.

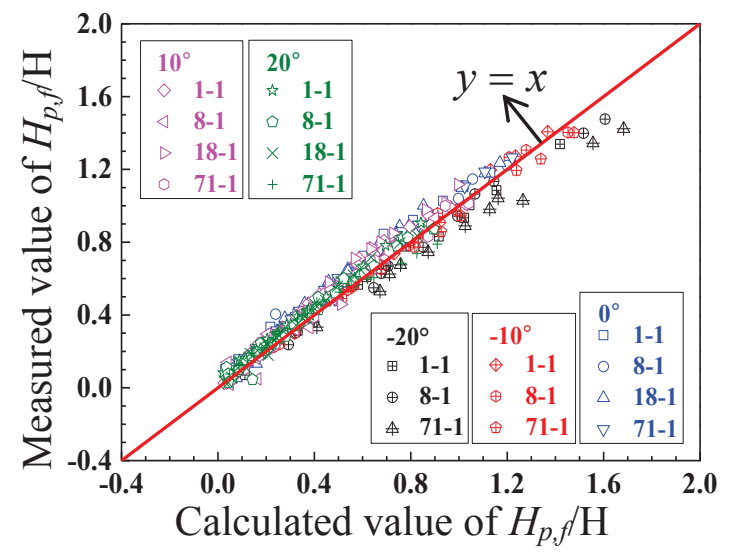

Figure 9: Comparison of predicted impinging flame lengths in $y$ direction (Eq. (7)) with measured values. 


\section{Conclusions}

This paper investigates the impinging flame lengths beneath an inclined ceiling induced by a wall-attached fire. Flame lengths in $x$ direction ( $H_{n, f}$, normal to wall-ceiling intersection) and that in $y$ direction $\left(H_{p, f}\right.$, parallel to intersection) are measured experimentally and correlated based on the physical nature of such impinging flow structure. It is noted that due to the gravitational component along the ceiling (with inclined ceiling) as well as the rotating vortex flows induced at the wallceiling junction corner area (wall-attached fire), it results in an impinging ceiling flow structure essentially different from that reported previously. The major findings are:

(1) The impinging flame length in $x$ direction increases, whereas that in $y$ direction decreases with the increasing of the ceiling inclination angle. This is due to the opposite effect of buoyancy (gravitational) component along ceiling on the impinged flow structure hence un-burnt fuel distribution in two directions (Figs. 3-5).

(2) The ceiling inclination effect on this fire impinging configuration can be well represented by buoyancy component along ceiling, or namely, $\sin (\theta)$. The normalized impinging flame length in $x$ direction $\frac{H_{n, f}}{H}$ correlates well to $\frac{1+\sin (\theta)}{2} \frac{H_{\text {wall, }, H}-H}{H}$ (Eq. (5) and Fig. 7), while that in $y$ direction $\frac{H_{p, f}}{H}$ correlates well to $\frac{H_{\text {wall }, f}-H}{H} / \frac{1+\sin (\theta)}{2}$ (Eq. (7) and Fig. 9).

(3) The inclination angle has little effect on the product of $\frac{H_{n, f}}{H} \times \frac{H_{p, f}}{H}$ (Fig. 8) because the inclination angle has opposite effects on the un-burnt fuel distribution in $x$ direction and that in $y$ direction. This value is found to be just a square function of $\frac{H_{\text {wall }, f}-H}{H}$ (Eq. (6)). 


\section{Acknowledgements}

This work was supported by Key project of National Natural Science Foundation of China under Grant No. 51636008, NSFC-STINT joint project (USTC-Lund University), Key Research Program of Frontier Sciences, Chinese Academy of Science (CAS) under Grant No. QYZDB-SSW-JSC029 and Fundamental Research Funds for the Central Universities under Grant No. WK2320000035 and WK2320000038.

\section{Reference}

[1] G. Heskestad, M.A. Delichatsios, Proc. Combust. Inst. 17 (1) (1979) 1113-1123.

[2] M.A. Delichatsios, Combust. Flame 43 (1981) 1-10.

[3] H.Z. You, G.M. Faeth, Fire Mater. 3 (3) (1979) 140-147.

[4] G. Heskestad, T. Hamada, Fire Safety J. 21 (1993) 69-82.

[5] H.W. Ding, J.G. Quintiere, Fire Safety J. 52 (2012) 25-33.

[6] Y.D. Wang, A. Vouros, J.P. Zhang, M.A. Delichatsios, J. Loss Prevent. Proc. 49 (2017) 652-659.

[7] V. Babrauskas, Fire Mater. 4 (3) (1980) 119-126.

[8] D. Gross, Fire Safety J. 15 (1) (1989) 31-44.

[9] B.Y. Lattimer, Fire Technol. 49 (2013) 269-291.

[10] Z.H. Gao, J. Ji, H.X. Wan, K.Y. Li, J.H. Sun, Proc. Combust. Inst. 35 (3) (2015) 2657-2664.

[11] X.C. Zhang, H.W. Tao, W.B. Xu, X.L. Zhang, L.H. Hu, Combust. Flame 176 (2017) 349-357.

[12] B. Karlsson, J.G. Quintiere, Enclosure fire dynamics, CRC Press LLC, 2000.

[13] P.L. Hinkley, H.G.H. Wraight, C.R. Theobald, Fire Safety J. 7 (1984) 227-242.

[14] Y. Oka, O Imazeki, Fire Safety J. 65 (2014) 41-52.

[15] Y. Oka, O Imazeki, Fire Safety J. 65 (2014) 53-61.

[16] Ministry of Housing and Urban-Rural, General Administration of Quality Supervision, Inspection and Quarantine, Technical Code for Roof Engineering GB 50345-2012, The State Standard of the People's Republic of China.

[17] M.A. Delichatsios, Combust. Flame 92 (1993) 349-364. 
[18] B. Merci, T. Beji, Fluid mechanics aspects of fire and smoke dynamics in enclosures, CRC press LLC, Boca Raton, USA, 2016.

[19] K. Noto, K.Teramoto, T.Nakajima, J. Thermophys. Heat Trans.13 (1999) 82-90.

[20] K.H. Lu, L.H. Hu, M.A. Delichatsios, F. Tang, Z.W. Qiu, L.H. He, Proc. Combust. Inst. 35 (2015) 2615-2622.

[21] E.E. Zukoski, B.M. Cetegen, T. Kubota, Proc. Combust. Inst. 20 (1985) 361-366.

[22] N. Otsu, IEEE Trans. Syst. Man Cybern. 9 (1979) 62-66.

[23] A.V. Singh, M.J. Gollner, Combust. Flame 162 (2015) 2214-2230.

[24] Y. Oka, O. Imazeki, O. Sugawa, Fire Safety J. 45 (4) (2010) 221-227.

[25] P. Chatterjee, K.V. Meredith, Y. Wang, Fire Safety J 91 (2017) 461-470.

[26] Y. Hasemi, T. Tokunaga, Fire Sci. Techno., 4 (1) (1984) 15-26. 


\section{Figure captions}

Fig. 1: Experimental setup.

Fig. 2: Impinging flame length quantification in the two directions (burner: $16.88 \mathrm{~mm}(L) \times 16.88$ $\mathrm{mm}(W) ; H=0.57 \mathrm{~m} ; \dot{Q}=13.39 \mathrm{~kW})$.

Fig. 3: Measured impinging flame lengths in the two directions versus heat release rates (burner: $16.88 \mathrm{~mm} \times 16.88 \mathrm{~mm} ; H=0.57 \mathrm{~m})$ for various ceiling inclination angles.

Fig. 4: Physics of buoyancy effect (gravitational component along ceiling) on the impinging flame lengths at negative (a) and positive (b) ceiling inclination angles.

Fig. 5: The isotherms (Unit: ${ }^{\circ} \mathrm{C}$ ) of ceiling inclination angles $-20^{\circ}, 0^{\circ}$ and $20^{\circ}$ (burner: $16.88 \mathrm{~mm} \times$ $16.88 \mathrm{~mm} ; H=0.57 \mathrm{~m} ; \dot{Q}=13.39 \mathrm{~kW})$.

Fig. 6: (a) Normalized impinging flame lengths in the $x$ direction versus the normalized cut-off flame height and comparison with previous data [11] as well as the correlations proposed in $[6,9]$ for free fire impingement without the effect of the wall for horizontal ceiling; and (b) for all inclination angles.

Fig. 7: Normalized impinging flame lengths in $x$ direction versus the modified normalized cut-off wall flame height $\left(H_{\text {wall }, f} H\right) / H$ including the effect of ceiling inclination angle.

Fig. 8: Plot of $\frac{H_{n, f}}{H} \times \frac{H_{p, f}}{H}$ against the normalized cut-off wall flame height $\left(H_{w a l l, f} H\right) / H$ for various ceiling inclination angles.

Fig. 9: Comparison of predicted impinging flame lengths in $y$ direction (Eq. (7)) with measured values. 